\title{
An acute care unit for elderly medical patients did not increase hospital costs
}

\author{
Covinsky KE, King Jr JT, Quinn LM, et al. Do acute care for elders units increase hospital costs? A cost analysis using the hospital \\ perspective.J Am Geriatr Soc 1997 Jun;45:729-34.
}

\section{Objective}

To determine the hospital costs of caring for medical patients in a special unit for older people designed to maintain or achieve independence in self care activities compared with usual ward care.

\section{Design}

Formal cost analysis of hospital costs taken from data in a randomised controlled trial.

\section{Setting}

The general medical service of a university hospital in the USA.

\section{Patients}

650 patients in hospital who were aged $\geqslant 70$ years (mean age $80 \mathrm{y}, 67 \%$ women, $41 \%$ non-white, $40 \%$ independent in activities of daily living [ADL] at admission). Patients admitted to the intensive care unit or subspecialty medical wards were excluded.

\section{Intervention}

All patients were assigned a primary nurse, house staff, and an attending physician. 326 patients were admitted to the acute care for elders unit and 324 to usual ward care. The acute care for elders unit included patient centred care, planning for discharge, and input from social workers, physical and occupational therapists, and dietitians. The acute care for elders unit was designed to help patients maintain or achieve independence in basic ADL function. Both units had similar staff ratios and access to existing hospital services.

\section{Main outcome and cost measures}

Improvement in ADL function. Costs were obtained from hospital financial records and represent actual resources used during each patient service or procedure. Indirect costs, fixed and variable direct costs, and costs for developing and maintaining the intervention were calculated for each patient.

\section{Main results}

A previous study report showed increased ADL function in patients in the acute care for elders unit. Daily costs of the intervention were calculated to be US $\$ 38.43$ per patient. The groups did not differ for total mean daily costs $(\$ 876$ for acute care for elders unit $v \$ 847$ for usual care, $\mathrm{p}=0.08$ ), mean cost per admission ( $\$ 6608 v \$ 7240, \mathrm{p}=0.9)$, or length of stay (7.5 v $8.4 \mathrm{~d}$, $\mathrm{p}=0.4$ ). Sensitivity analysis showed that only when the daily cost of the intervention was higher than $\$ 123$ per patient would the mean cost for intervention patients exceed that of usual care patients.

\section{Conclusion}

A hospital based geriatric ward intervention for medical patients aged 70 years or older improved functional outcomes with no increase in hospital costs.

Sources of funding: National Institute on Aging and the John A Hartford Foundation.

For article reprint: $\operatorname{Dr} K$ E Covinsky, Division of General Internal Medicine and Health Care Research, University Hospitals of Cleveland, 11100 Euclid Avenue, Cleveland, OH 44106 USA. Fax +12163680737

\section{Commentary}

This is a timely study given the growing debates about the cost of providing services for older people. Will the increased burden on health care providers resulting from the growing, increasingly dependent, aging population cause an increase in health care costs?

The study by Covinsky et al raises the issue of the "real" costs associated with the provision of effective and efficient gerontological services. The study clearly shows improvements in functional status at no increase in costs. This finding concurs with that of a recent systematic review of stroke unit care. ${ }^{1}$ Studies such as these continue to show the value of effectively coordinated interdisciplinary gerontological rehabilitation services.
In an era when major emphasis is being placed on reducing admission to secondary care and increasing primary care services, this study has important implications. While the study is limited by not providing costs of particular rehabilitation interventions, it clearly shows the importance of an effectively coordinated interdisciplinary team. Therefore, a focus on shifting services to the community without considering this type of team approach may be ineffective from an economic and health care outcome perspective. For nursing in particular, the study again raises the important role of nursing in rehabilitation and concurs with previous studies. ${ }^{2}$

The outcomes of this study, improved function at no increase in costs with specialist rehabilitation services, need to be considered by health care planners in their decisions to reorganise services. Future research should focus on the evaluation of community based coordinated interdisciplinary gerontological rehabilitation services.

Brendan McCormack, RN Director, Community Hospitals and Gerontological Nursing Programme Royal College of Nursing Institute

Oxford, UK

1 Stroke Unit Trialists Collaboration. Collaborative systematic review of the randomised trials of organised inpatient (stroke unit) care after stroke. BMJ 1997;314:1151-9

2 Evans LK, Yurkow J, Siegler EL. The CARE Program: a nurse managed collaborative outpatient program to improve function of frail older people. Collaborative assessment and rehabilitation for elders. J Am Geriatr Soc 1995;43:1155-60. 